This paper has been accepted for publication at

SOCIAL PSYCHOLOGY

Stefanczyk, M., Rokosz, M., \& Białek, M (2021). Mere ownership effect is equally pronounced in material and immaterial objects. Social Psychology

\title{
Mere ownership effect is equally pronounced in material and immaterial objects
}

Michał Stefańczyk, Marta Rokosz, and Michał Białek

Institute of Psychology, University of Wrocław

\begin{abstract}
:
The mere ownership effect is an increase in the subjective value of owned objects compared to identical but non-owned objects. We tested whether the effect differs in magnitude between material and immaterial objects (e.g., information). Three hundred participants played an incentivized detective game in which they had to connect clues to identify a murderer. Their task was to evaluate the usefulness of the clues they or their partners were endowed with. Despite the fact that the immaterial clues were rated as more useful than the material ones, we found the mere ownership effect to be similarly strong for the material and the immaterial clues.
\end{abstract}

Keywords: mere ownership effect, endowment effect, immaterial objects, heuristics and biases 


\section{Mere ownership effect is equally pronounced in material and immaterial objects}

\section{ABSTRACT:}

The mere ownership effect is an increase in the subjective value of owned objects compared to identical but non-owned objects. We tested whether the effect differs in magnitude between material and immaterial objects (e.g., information). Three hundred participants played an incentivized detective game in which they had to connect clues to identify a murderer. Their task was to evaluate the usefulness of the clues they or their partners were endowed with. Despite the fact that the immaterial clues were rated as more useful than the material ones, we found the mere ownership effect to be similarly strong for the material and the immaterial clues.

Keywords: mere ownership effect, endowment effect, heuristics

In an experiment by Beggan (1992), participants were asked to evaluate several products, e.g., chocolate, peanut brittle, playing cards, or a mug insulator in terms of its attractiveness, value, and quality of design. Some of them were promised to receive the insulator as a gift, while others were promised to receive an equally valuable product which was not evaluated. The results showed that participants who were to receive the insulator rated it much more positively than those who were promised a different reward. This experiment was first to show that people add value to an object simply because they own it, an effect termed the mere ownership effect (Morewedge et al., 2009; Reb \& Connolly, 2007). Mere ownership effect does not require actual, physical ownership (Nancekivell et al., 2019). For instance, people can feel ownership towards things they cannot possess, such as name letters (Nuttin Jr, 1987) or ideas (Shaw et al., 2012).

Several factors moderate the mere ownership effect (Białek et al., 2020). For instance, it does not require factual ownership and can be a result of subjective feelings based on an implied ownership (Reb \& Connolly, 2007; Nikander et al., 2014). It tends to be stronger towards original objects rather than their similar replicas (Białek et al., 2020). However, most studies on this effect features tangible objects such as mechanical pencils (Peck \& Shu, 2009), coffee mugs (Morewedge et al., 2009), or insulator mugs (Beggan, 1992). Mere ownership also applies to the ownership of immaterial objects such as self-generated design ideas in concept evaluation (Nikander et al., 2014), arguments in a discussion (De Dreu \& van Knippenberg, 2005), or information required for solving a criminal puzzle (Toma et al., 2013). Mere ownership effect distorts group decision-making because it leads people to overvalue owned arguments (Chernyshenko et al., 2003; De Dreu \& van Knippenberg, 2005) 
undervalue the information presented by others (Chernyshenko et al., 2003), and to be prejudiced to expected counterarguments (De Dreu et al., 2008).

In this project, we wanted to zoom in on the difference in the mere ownership effect in material vs immaterial objects. To our knowledge, there have been no experimental studies directly testing this problem. However, according to the meta-analysis's findings (Białek et al., 2020), the mere ownership effect tends to be stronger in studies investigating immaterial rather than material objects. This difference in the magnitude of the mere ownership effect, if true, would have far-reaching consequences. People are unwilling to trade between two objectively equal options if they own one of the two objects, and the asked price tends to be about 2.5 times larger than the willingness to pay (Horowitz \& McConnell, 2002). For instance, when half of the experiment participants were awarded a chocolate bar, owners valuated it at $3.98 \$$, whereas non-owners valuated it at $1.25 \$$ (Kahneman et al., 1990). If the mere ownership effect is even larger in immaterial objects, people would be greatly unwilling to part with their favourite ideas, solutions, and theories just because of the feeling of ownership. In turn, this feeling of ownership can slow down socio-political or scientific progress.

With this study, we aimed to compare the mere ownership effect's sizes in immaterial and material objects. The study was put in a cooperative setting of an incentivized detective game. In line with the meta-analysis findings (Białek et al., 2020), we expected the mere ownership effect to be stronger for immaterial, rather than material objects.

\section{The Experiment}

\section{Method}

Participants solved a detective problem in groups of three. They were randomly assigned to one of the two experimental conditions: immaterial $(n=150)$ and material $(n=150)$, and to one of the three clues sets. The experiment was preregistered (https://aspredicted.org/he6bx.pdf). Data and materials are available at the OSF.io (https://osf.io/sreyh/). Statistical analyses were performed using jamovi, version 1.8 (The jamovi project, 2021).

\section{Participants}

We analysed data from 300 people (65\% women; $M_{\text {age }}=25.1$; range 18-71). However, we recruited 330 individuals and excluded 10 three-persons groups because they misrepresented some of the clues' (see Procedure and Materials for details). The 
participants, recruited through a snowball sampling method, were divided into groups of three on the basis on their preferences of a time slot. Our sample size provided $80 \%$ power to detect between-subject effect size of $d=0.28$, which is smaller than the expected effect based on the meta-analysis (Białek et al., 2020), namely 0.59 [0.47, 0.70].

\section{Incentives}

The participants were incentivized. Specifically, on top of a flat show-up fee (10PLN, about $\$ 2.5)$, they could earn additional 15PLN if they collectively identified the murderer in the detective game.

\section{Procedure and Materials}

The study was conducted online, using video meetings platform Zoom. The participants, in groups of three, were asked to identify the murderer in a detective game, loosely based on a crime investigation used in Toma and Butera (2009). The game described a murder case with four suspects. On top of shared information describing the case, each participant owned a unique set of three clues. Each set of clues was designed to cast suspicion on one of the characters. The murderer was the fourth person that also appeared in the story but was not the primary suspect in any of the set of clues.

The experimental manipulation was that the clues were either presented as immaterial or material objects. For example, the participants were told they heard the murderer saying something critical for the investigation (immaterial condition), or were told they possess a police report of a murderer saying the same thing (material condition). This way, the content of each clue was identical (content of the confession), but the tangibility of each clue was manipulated.

The participants' task was to identify the murderer (primarily as a group, but also individually) and to evaluate the usefulness of all clues (3 owned and 6 non-owned) using a 10-point Likert scale (individually, after the group discussion described below).

The participants were given five minutes to familiarize themselves with the instruction $(\sim 320$ words), the shared information ( 260 words) and with their individual clues ( 90 words per clue set). Subsequently, based on their incomplete information, the participants were asked to individually point at their primary suspect to the experimenter in a private message. Considering the average reading speed (Brysbaert, 2019) we decided that 5 minutes is just enough to get acquainted with the content of the text, but not to get too familiar with it through multiple re-readings (thus, reducing the mere exposure effect; Zajonc, 1968). Next, 
the participants started a 15-minutes-long group discussion, during which they argued about the identity of the murderer and shared all of their unique information. After 10 and 14 minutes, the participants were reminded about the remaining time. They were asked to paraphrase their clues rather than to show, read word-to-word, or write their clue sets. The groups in which the participants misreported their clues were excluded from the analyses. We did this to minimize the risk of confounding reliability of the clues shared by others with ownership. That would mean that the clues of others were rated as less useful because they were told in an unreliable way, whereas own clues were put straightforwardly in the text. After the discussion, the participants were given an individual link to a short survey asking demographic information, the group decision regarding the murderer, and their individual impression about his/her identity. In the end, the participants individually evaluated the usefulness of all nine clues in a fixed order. Subsequently, the group was informed about who the real murderer was.

\section{Results}

Prior to the group discussion, over a half $(52.3 \%)$ of the participants pointed at the cued person as their suspect, while only $14 \%$ speculated the correct suspect. The task was moderately challenging, with $72.3 \%$ of teams and $71.3 \%$ of individual calls identifying the correct person as a murderer. The groups with material vs immaterial clues were similarly successful, $t(298)=1.42, p=.157$. Likewise, the accuracy of individual responses rather than group responses was robust to the materiality of a cue, $t(298)=0.00, p=1$. Because there were no control participants not-owning any clues, we could not test whether ownership distorted the group performance.

Overall, the clues presented to the participants were all found to be quite useful $(M=7.23$, $S D=2.35)$, with each clue set judged as similarly useful, $F(2,2694)=0.06, p=.941$. Although some clues were found more useful than the others, $F(8,2682)=50.85, p<.001$, this had likely no impact on our ownership effect analysis because, regardless of its baseline usefulness, each clue was presented to the participants either as owned or as non-woned, and as material or as immaterial. See supplementary materials for detailed analysis.

As preregistered, we submitted our data to a linear mixed effect model to estimate the differences in perceived usefulness of the clues (dependent variable, scale 1 to 10). Fixed effects were: type of a clue (material or immaterial; between-subject), and ownership status of a clue (owned, non-owned; within-subject), and their interaction. The content of a clue (9 different clues), and participant ID were cluster variables. The order in which the clues were discussed (within-subject) was a covariate. All factors were contrast-coded as -0.5 and +0.5 . 
Table 1. Results of Linear Mixed Effects Models

\begin{tabular}{lcccc}
\hline & \multicolumn{2}{c}{ Model 1 } & \multicolumn{2}{c}{ Model 2 } \\
\hline \multicolumn{1}{c}{ Factors and covariates } & $b$ & $95 \%$ CI & $b$ & $95 \%$ CI \\
Intercept & $7.29^{* * *}$ & $6.70,7.88$ & $7.22^{* * *}$ & $6.62,7.81$ \\
Ownership (yes-no) & $0.34^{* * *}$ & $0.18,0.50$ & $0.30^{* * *}$ & $0.12,0.48$ \\
Materiality (yes-no) & $-0.30^{*}$ & $-0.56,-0.06$ & -0.28 & $-0.55,0.01$ \\
Ownership*Materiality & 0.10 & $-0.22,0.42$ & 0.17 & $-0.19,0.54$ \\
Order (1 to 9) & -0.02 & $-0.06,0.01$ & -0.02 & $-0.06,0.01$ \\
Victory (yes - no) & - & - & $0.32^{*}$ & $0.04,0.59$ \\
Ownership*Victory & - & - & 0.18 & $-0.19,0.54$ \\
Materiality*Victory & - & - & -0.02 & $-0.57,0.53$ \\
Ownership*Materiality*Victory & - & - & -0.26 & $-0.98,0.47$ \\
\hline \multicolumn{1}{r}{ Cluster variables } & Variance & ICC & Variance & ICC \\
ID & 0.68 & .14 & 0.67 & .14 \\
Clue & 0.78 & .16 & 0.78 & .16 \\
\hline Note: ${ }^{* * *} \mathrm{p}<.001,{ }^{* *} \mathrm{p}<.01,{ }^{*} \mathrm{p}<.05$ & & & &
\end{tabular}

As shown in Table 1 Model 1, the participants found the clues they owned as more useful that those non-owned, and the immaterial clues as more useful than the material ones. These two effects did not interact, suggesting the mere ownership effect is independent from the materiality of a clue. A potential confound is that some teams could have valued the clues differently if they succeeded in the task because their members experienced a feeling of rightness (Thompson et al., 2011), masking this way the other effects. After accounting for this victory effect (Model 2) the results did not change significantly, other than showing that members of victorious (vs. unsuccessful) teams found all clues more useful. Thus, the victory effect did not influence our main conclusions regarding the impact of mere ownership on usefulness ratings. 
Figure 1. Usefulness ratings depending on the clues' properties

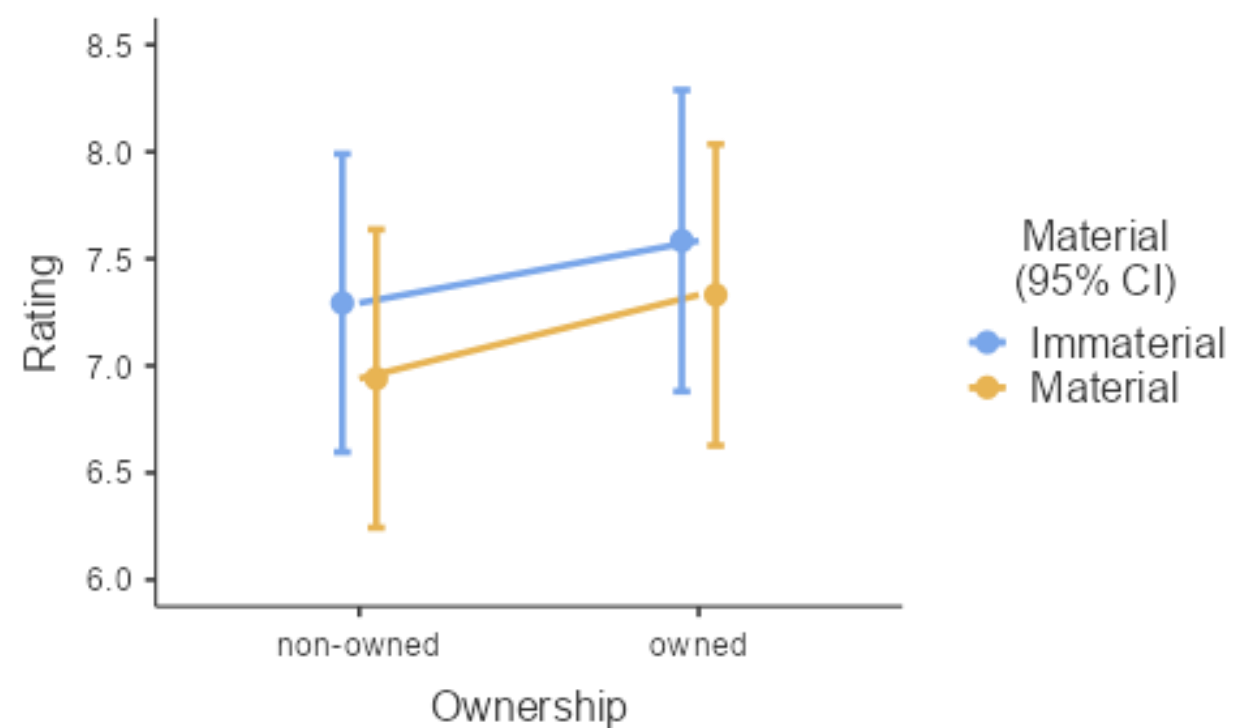

\section{Discussion}

In the current experiment, people found the owned vs non-owned clues more useful, confirming the mere ownership effect. However, the observed effect size is relatively small (mean difference in perceived usefulness between owned and non-owned objects was about 0.3 point on a 10-point scale). This effect was of similar magnitude in the material and the immaterial clues. The participants rated the clues as more useful when they succeded in a task, and when the clues were immaterial rather than material.

Contrary to the meta-analysis (Białek, et al., 2020), our study does not provide evidence that the mere ownership effect is stronger in immaterial objects. The confidence interval for the interaction included small effect sizes in one way or in the other, leaving the results in this subject inconclusive. However, the mataanalysis did not include any studies that directly compared the magnitude of the mere ownership effect between material and immaterial objects; it merely estimated its effect size in studies with material/immaterial objects. A possible confound in the meta-analysis is the subjective usefulness and importance of an object: e.g., in Knetsch (1989) a material object was a bar of chocolate, whereas in De Dreu \& van Knippenberg (2005) the immaterial object was an argument important in a discussion; or in Toma et al. (2013) the immaterial object was a relevant piece of evidence. In our experiment, the importance of objects was held constant, eliminating the difference in magnitude of the mere ownership effect in material vs immaterial objects.

The advancement gained by this research is the first ever direct comparison of the magnitude of the mere ownership effect in material and immaterial objects. Not only do we show that people overvalue owned ideas just as they overvalue owned objects, but we 
report that the effect is non-smaller in immaterial objects compared to material objects in which the prototypical mere ownership effect was first found. Thus, all the biases associated with ownership of material objects can be extended to ownership of ideas and information. This has direct application to the human decision-making process. Specifically, people overvalue objects they own and are unwilling to part with them unless they are offered something overwhelmingly better than the objective valuation of the owned object (Horowitz \& McConnell, 2002). In the light of the current result, we can assume that people in certain contexts would also be unwilling to trade their ideas and information for ideas and information of others, unless the other information is much more useful and valuable. Let us consider the practical implications of such a bias. Imagine you have designed a theory which gained some recognition. You and people who invested their time and effort in working on this theory application could have developed a feeling of ownership over it. Then, a promising alternative model is proposed, but it lacks thorough empirical support your theory has gained over time. You may be setting a much greater threshold of evidence for the new theory than for your theory, so that the new one has to be much better at explaining real-world phenomena to make you consider abandoning your own theory. It is not that you are dishonestly comparing the two models. You suffer a mere ownership bias inflating the subjective value of the owned model to the extent you are dismissive to the new developments. Some archaic ideas could have survived much too long simply because of the collective mere ownership effect. Our current research cannot address this issue fully one would be required to add a control condition in which no ownership over the clues exists, e.g., all clues are presented as common, shared information.

Regarding our other observed effect - that the immaterial clues were found more useful than the material clues - we have no satisfying explanation for it. It may be an artifact of the procedure, i.e., the immaterial clues were more valuable because they were associated with some additional expert or source of information. To illustrate, in the experiment you either found a pair of shoes covered in blood, or had it reported to you from a police laboratory. Maybe the expert constituted some additional value. Regardless if this explanation is true, we found it not to interact with the mere ownership effect, hence we leave this question aside for now.

Our study has to be taken with a dose of caution. We only ran one experiment in a specific context of cooperation. Specifics of our design could have prevented us from detecting the true difference in the mere ownership effect between material and immaterial objects. Moreover, the clues that were meant to be material were in fact information about the materiality of the object. Thus, the participants could have treated all clues as immaterial. However, our participants rated the usefulness of the material and immaterial the clues 
differently. It could be due to the perceived (im)materiality of an object, or due to the social proof and/or authority phenomenon legitimizing the importance of the immaterial evidence (Cialdini, 2009). Because of this potential confound, future studies might ensure the tangibility of material objects, e.g. create a game similar to an escape room design, in which clues are given in a physical form (a blood-stained shoe) or as an immaterial information. Moreover, a risk of additional influence of mere exposure effect on our results must be attended. However, the exposure effect appears only after repeated exposures (Beggan, 1992; Zajonc, 1968), and it influences one's preferences, whereas it is mere ownership effect that influences one's valuation (Tom et al., 2007), just like in our study. Finally, because the participants rated the clues after the group discussion, it is possible that this has masked effects of ownership, materiality, or their interaction. Future studies may consider a 'single-player' version of the study, in which a participant is told which clues are theirs, and which are not, and then rates their usefulness.

To summarize, we cannot be trusted with rating our possessions objectively, be it a material mug, an immaterial murder clue, or a scientific theory. The real value of material and immaterial objects that we have associated with ourselves becomes inflated by a nonobjective extra-value through the mere ownership bias. 


\section{References}

Beggan, J. K. (1992). On the Social Nature of Nonsocial Perception: The Mere Ownership Effect. Journal of Personality and Social Psychology, 62(2), 229-237. https://doi.org/10.1037/0022-3514.62.2.229

Białek, M., Gao, Y., Yao, D., \& Feldman, G. (2020). Owning leads to valuing: Meta-analysis of the Mere Ownership Effect. Preprint. https://doi.org/10.13140/RG.2.2.13568.33287/2

Brysbaert, M. (2019). How many words do we read per minute? A review and meta-analysis of reading rate. Journal of Memory and Language, 109, 104047.

Chernyshenko, O. S., Miner, A. G., Baumann, M. R., \& Sniezek, J. A. (2003). The impact of information distribution, ownership, and discussion on group member judgment: The differential cue weighting model. Organizational Behavior and Human Decision Processes, 91(1), 12-25. https://doi.org/10.1016/S0749-5978(02)00533-2

Cialdini, R. (2009). Influence: The psychology of persuasion. HarperCollins New York, NY.

De Dreu, C. K. W., Nijstad, B. A., \& van Knippenberg, D. (2008). Motivated Information Processing in Group Judgment and Decision Making. Personality and Social Psychology Review, 12(1), 22-49. https://doi.org/10.1177/1088868307304092

De Dreu, C. K. W., \& van Knippenberg, D. (2005). The possessive self as a barrier to conflict resolution: Effects of mere ownership, process accountability, and self-concept clarity on competitive cognitions and behavior. Journal of Personality and Social Psychology, 89(3), 345-357. https://doi.org/10.1037/0022-3514.89.3.345

Horowitz, J. K., \& McConnell, K. E. (2002). A Review of WTA/WTP Studies. Journal of Environmental Economics and Management, 44(3), 426-447. https://doi.org/10.1006/jeem.2001.1215

Kahneman, D., Knetsch, J. L., \& Thaler, R. H. (1990). Experimental tests of the endowment effect and the Coase theorem. Journal of Political Economy, 98(6), 1325-1348.

Knetsch, J. L. (1989). The Endowment Effect and Evidence of Nonreversible Indifference Curves. The American Economic Review, 79(5), 1277-1284.

Morewedge, C. K., Shu, L. L., Gilbert, D. T., \& Wilson, T. D. (2009). Bad riddance or good rubbish? Ownership and not loss aversion causes the endowment effect. Journal of 
IMMATERIAL OWNERSHIP

Experimental Social Psychology, 45(4), 947-951.

https://doi.org/10.1016/j.jesp.2009.05.014

Nancekivell, S. E., Friedman, O., \& Gelman, S. A. (2019). Ownership Matters: People

Possess a Naïve Theory of Ownership. Trends in Cognitive Sciences, 23(2), 102-

113. https://doi.org/10.1016/j.tics.2018.11.008

Nikander, J. B., Liikkanen, L. A., \& Laakso, M. (2014). The preference effect in design concept evaluation. Design Studies, 35(5), 473-499.

https://doi.org/10.1016/j.destud.2014.02.006

Nuttin Jr, J. M. (1987). Affective consequences of mere ownership: The name letter effect in twelve European languages. European Journal of Social Psychology, 17(4), 381402.

Peck, J., \& Shu, S. B. (2009). The effect of mere touch on perceived ownership. Journal of Consumer Research, 36(3), 434-447.

Reb, J., \& Connolly, T. (2007). Possession, feelings of ownership and the endowment effect. Judgment and Decision Making, 2(2), 107-114.

Shaw, A., Li, V., \& Olson, K. R. (2012). Children Apply Principles of Physical Ownership to Ideas. Cognitive Science, 36(8), 1383-1403. https://doi.org/10.1111/j.1551$6709.2012 .01265 . x$

The jamovi project (2021). jamovi. (Version 1.8) [Computer Software]. Retrieved from https://www.jamovi.org.

Tom, G., Nelson, C., Srzentic, T., \& King, R. (2007). Mere exposure and the endowment effect on consumer decision making. The Journal of Psychology, 141, 117-125.

Toma, C., \& Butera, F. (2009). Hidden Profiles and Concealed Information: Strategic Information Sharing and Use in Group Decision Making. Personality and Social Psychology Bulletin, 35(6), 793-806. https://doi.org/10.1177/0146167209333176

Toma, C., Bry, C., \& Butera, F. (2013). Because l'm worth it! (more than others...): Cooperation, competition, and ownership bias in group decision-making. Social Psychology, 44(4), 248-255. https://doi.org/10.1027/1864-9335/a000109

Zajonc, R. B. (1968). Attitudinal effects of mere exposure. Journal of Personality and Social Psychology, 9(2, Pt.2), 1-27. https://doi.org/10.1037/h0025848 


\section{SUPPLEMENTARY MATERIALS}

To see whether our sets of clues efficiently suggested an incorrect suspect, we present a contingency table. Highlighted cells present proportion of individuals who suspected the suspect we intended to suggest to them.

Its analysis suggests that each clue indeed suggested different suspect, and only after the discussion teams moved to identify the correct suspect: moving from only $14 \%$ of participants suspecting someone else prior to the discussion to $73 \%$ afterwards.

Table 1.

Percentages of speculated murderers based on only 3 clues possessed by participant, prior to learning additional 6 clues and to the group discussion.

\begin{tabular}{lllll}
\hline Clue set & Angus & Bigfoot & Constance & Someone else \\
\hline Delta & 27 & 8 & 45 & 19 \\
Juliette & 34 & 40 & 14 & 12 \\
Tango & 72 & 10 & 7 & 11 \\
\hline total & 44.3 & 19.7 & 22 & 14 \\
\hline
\end{tabular}


To compare the overall usefulness of clue sets, we compared them without controlling for their materiality using ANOVA, with IV = clue set. We found that each clue set was rated as similarly useful. Thus, the results of the mere ownership analysis are not confounded by one set of clues being perceived as distinctively better or worse than the other sets.

\section{ANOVA DV = usefulness ratings; IV = clue set}

ANOVA - Rating

\begin{tabular}{lrrcrc} 
& Sum of Squares & df & Mean Square & F & p \\
\hline JDT & 0.672 & 2 & 0.336 & 0.0609 & 0.941 \\
Residuals & 14866.038 & 2697 & 5.512 & & \\
\hline
\end{tabular}

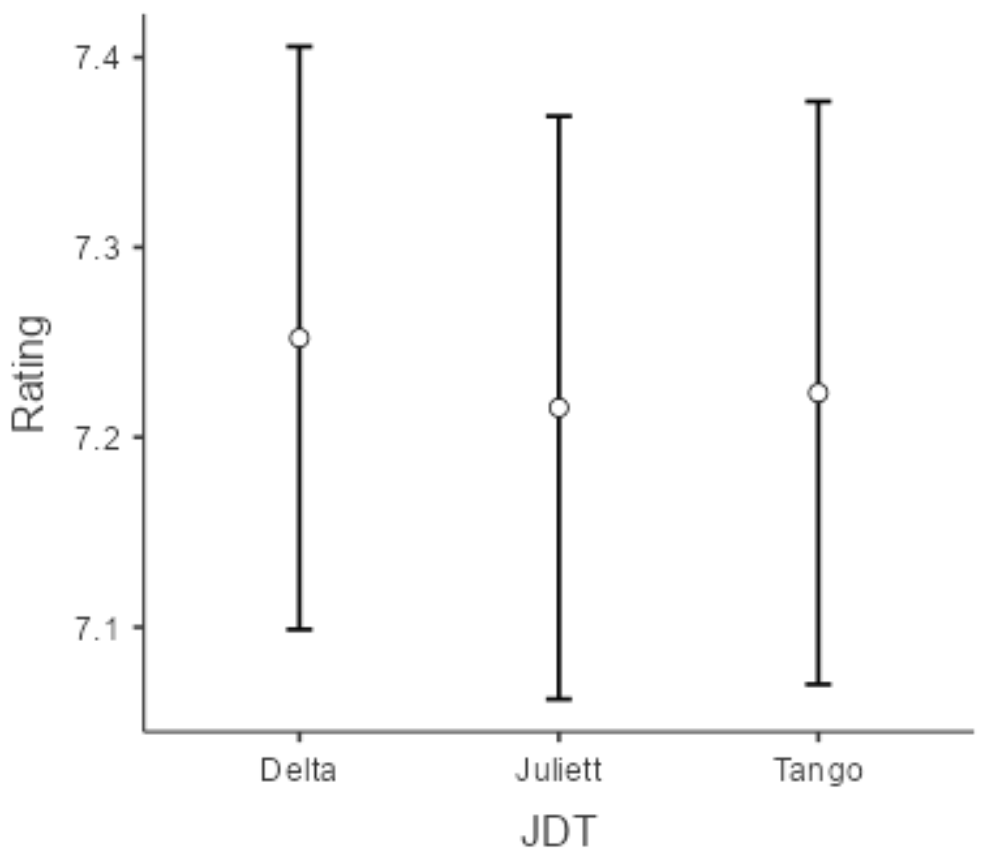


Next, we compared the usefulness of each clue independently to other clues using ANOVA, with IV = clue number. We found huge variability in the perceived usefulness of these clues. However, as the prior analysis shows, on average the sets were still perceived as similarly useful.

\section{ANOVA, IV = Usefulness ratings, IV = clue number}

ANOVA - Rating

\begin{tabular}{lcrcrc}
\hline & Sum of Squares & df & Mean Square & $\mathbf{F}$ & $\mathbf{p}$ \\
\hline clue & 1935 & 8 & 241.85 & 50.3 & $<.001$ \\
Residuals & 12932 & 2691 & 4.81 & & \\
\hline
\end{tabular}

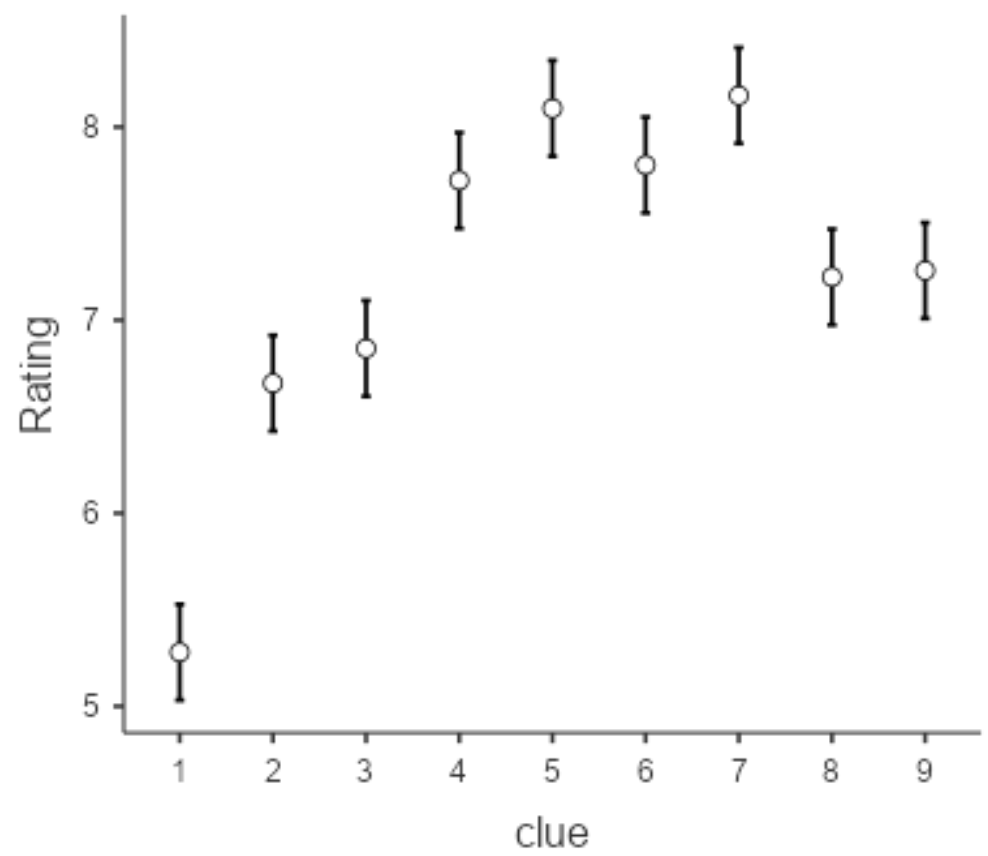


As suggested by the Reviewer, the test of the focal analysis can be completed using much simpler design ANOVA. Here, one condition is the average usefulness of 3 owned cues, and the other average usefulness of 6non-owned clues. The IV are 2 possession: yes/no $\times 2$ materiality: material/immaterial. The results of the ANOVA re presented below, and are fully consistent with the LME analysis reported in the main document: main effects of materiality and possession, and, no interaction.

Within Subjects Effects

\begin{tabular}{lrrrrr}
\hline & Sum of Squares & df & Mean Square & F & p \\
\hline MOE & 17.454 & 1 & 17.454 & 10.882 & 0.001 \\
MOE ** Material & 0.375 & 1 & 0.375 & 0.234 & 0.629 \\
Residual & 477.977 & 298 & 1.604 & & \\
\hline
\end{tabular}

Between Subjects Effects

\begin{tabular}{lrrrrr}
\hline & Sum of Squares & df & Mean Square & F & p \\
\hline Material & 13.8 & 1 & 13.80 & 5.63 & 0.018 \\
Residual & 731.0 & 298 & 2.45 & & \\
\hline
\end{tabular}

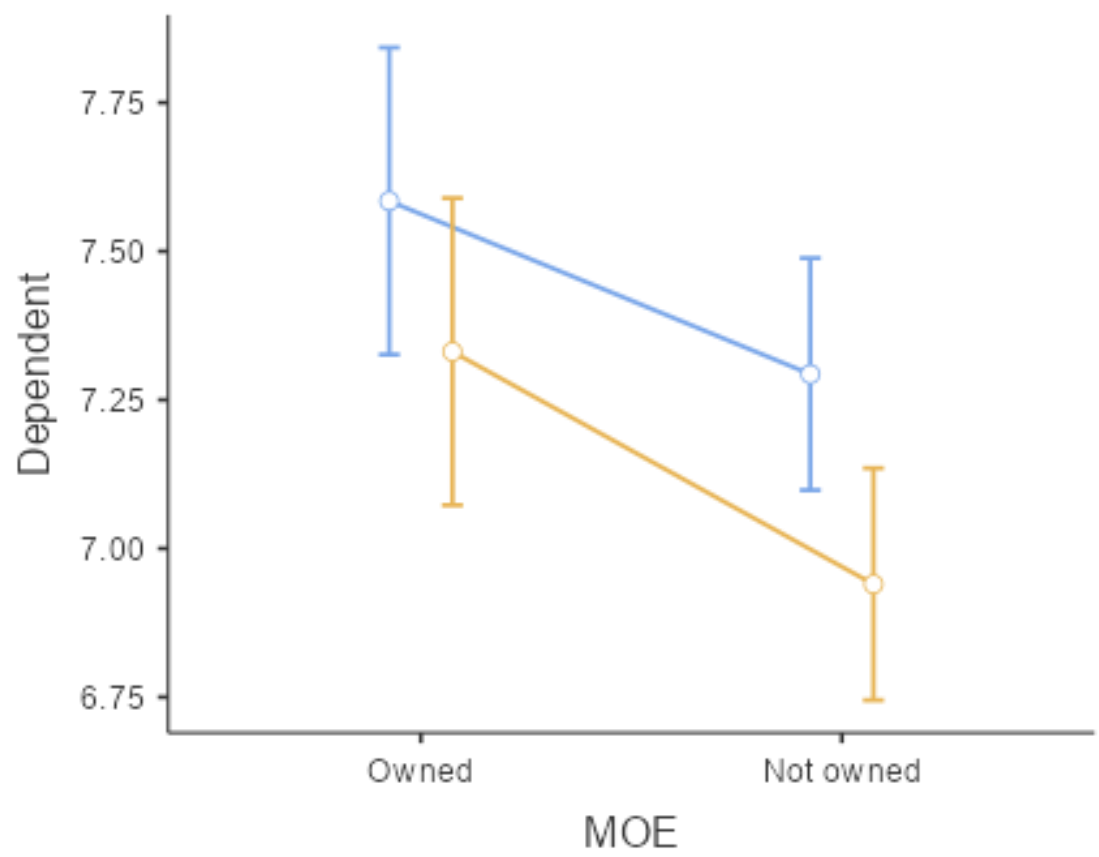

Material

$=1$

$=M$ 